\title{
Introduction: globalization and the community challenge
}

In recent years, there has been a huge upswing in the publication of books and essays on various aspects of the "loss of community." This theme reflects survey data showing large swaths of the European, and especially American, electorates who feel abandoned or betrayed, but most of all disconnected from traditional community attachments. This is reflected in "populist" movements in which citizens in a number of Western countries feel abandoned by those they perceive as uncaring elites; LePen in France, Brexit in Britain and Trump in the United States. Similar populist feelings appear to be at the root of the explosion of fundamentalist movements in the Middle East and Sub-Saharan Africa. A common element in all of this is the disruptive effect of globalization that weakens or destroys traditional communities, with accelerating speed each passing decade (Armstrong 2011; Taub 2016). Ironically, these reactionary movements are occurring during a period in which there has been a rise on a global level in material quality of life indicators (Pinker 2018).

The central theme of this book is that in order to effectively address community sustainability and reduce toxic inter-communal conflict it is most helpful to conceptualize the "community problem" as a "public goods" challenge, producing non-divisible costs affecting not only persons living in declining communities but also persons living in larger regional, national and international populations. The fundamental rationale for this approach is that it provides a path with which to obtain public support for the resources to meet community challenges through liberal democratic processes.

Much has been written, and many debates initiated, about the precise causal relationships between globalization and the challenges facing extant and future communities. For a sociologist, this is not a new topic. In fact, the core foundations of the discipline of sociology, and its major contribution, is found in the conceptualization of the community as a foundation of human existence. The problem with traditional sociological approaches to community, however, has been the failure to fully understand the role of formal institutions in strengthening and/or weakening communities. This is where a diverse collection of institutionally focused political scientists (E. Ostrom 2015; V. Ostrom 1991), economists (Buchanan and Tullock 1962; Collier 2018; Olson 1971), sociologists (Brinton, and Nee 1998) and a professor of humanities (Lilla 2017) offer 
a path to a more complete understanding of what supports sustainable communities. Even more important, this perspective provides a rationale with which to gain broader public support for the resources necessary for communities to meet the challenges of the 21 st century.

The starting point of an institutional approach to community sustainability is the concept of public goods (Olson 1971). The costs of weak and dysfunctional communities, as well as the persistence of zero-sum inter-community conflict affects not only members living in declining communities but a larger public that lives outside of those places. Later chapters will present a wealth of government data and social science documentation showing that lack of community attachment leads to costly public expenditures in areas of law enforcement, health, mental health, poverty and other areas that draw upon taxation of a cross-section of the larger population outside of the affected communities. Weak or dysfunctional communities lead to political alienation, a general distrust of liberal democratic political institutions and the much discussed "tribalism" that has infected public discourse (Bishop 2009, 2017). Alternatively, the data also show that placing individuals in healthy communities, regardless of their genetic or family backgrounds, can produce dramatic changes, not only in their personal lives, but also in reducing the costs for the larger citizenry (Chetty, Hendren and Katz 2016; Sampson 2012; Wilson 1980, 2012).

Because the negative effects of weak and dysfunctional communities cover a large swath of the citizenry, the latter fits Mancur Olson's (1971) classic definition of a large latent group. Unlike small groups, which rely on informal institutions and face-to-face social sanctions, achievement of collective non-divisible public goods in large latent groups requires some element of formal institutional enforcement.

\section{INFORMAL AND FORMAL INSTITUTIONS}

In the generic sense, institutions are the "blueprints" by which social groupings of human beings establish guidelines or boundaries for interaction, from the most intimate relationships to whole societies, as well as interactions between nations (Stanford Encyclopedia of Philosophy 2011). Informal institutions, which were the exclusive template for ensuring social order for much of human existence and remain so to a much greater extent than we often realize, can be a powerful force either facilitating or resisting community adaptation to the realities of the global change.

It is easy to provide illustrations of ways in which informal institutions can resist adaptation to exogenous changes. The comparative cross-national research by Inglehart and Norris (2003), shows that resistance to economic development can be rooted in the desire to preserve traditional community social organization; oftentimes, the maintenance of traditional patriarchal 
relationships between men and women. Moreover, these traditional views of what household and communities are supposed to look like also pose a barrier to men in accessing growing work opportunities in what have heretofore been defined as "women's work," such as nursing and elementary school teaching that could replace the lost manufacturing jobs that previously have been viewed as "men's work" (McGinn and Oh 2017).

At the same time, some informal institutional arrangements facilitate the adaptation to challenges created by external events. This is seen, for example, in the way in which community-wide social networks among German Catholics helped them to adapt to the farm crisis in the American Midwest in the mid-1980s. Because their primary goal was to maintain the family farm and ethnic community for future generations these farmers had a preference for more diverse but in the long run more sustainable agriculture than did their mono-cropping neighbors who focused more on short-term profits (Salamon 1985). Other ethnic groups, such as Japanese Americans, have been successful in maintaining strong communities and ethnic enterprises even while individuals in successive generations assimilate into American life, because group identity is based on a sense of common "peoplehood" rather than a specific language or religion (Fugita and O'Brien 1991; Reitz 1980).

Sociologists have long studied ways in which informal institutional arrangements affect community sustainability. This is seen, for example, in Floyd Hunter's (1953) classic study of the Community Power Structure in Atlanta, Georgia, that examines the role of non-elected "influential leaders," mainly from the business sector, who make important decisions about the future of a major American city. The role of informal leaders is equally, if not more, impactful in rural communities. In studies of the differential capacity of rural communities to respond effectively to economic crises caused by the loss of middle-size family farms in the mid- to late 1980 s, the leaders in the more adaptable, and therefore more sustainable, communities had more ties to one another that were built up over time through working together on projects. In these more resilient communities leaders also had more bridging ties to outside sources of information and material resources. It is noteworthy that the only personal characteristic of members of the leadership networks that had a positive effect on community viability was gender diversity, while a traditional "human capital" indicator education did not (O'Brien et al. 1991; O'Brien, Raedeke and Hassinger 1998). Findings from studies in both urban and rural settings around the world show that some mix of "bonding" - that is, close social networks ties - and "bridging" - that is, network links to outside information and material resources - social capital enables local communities to adapt to changing circumstances (Granovetter 1973; Woolcock and Narayan 2000). 
While informal institutions continue to play an important role in structuring social interactions today, as societies and the global order become more inter-dependent there has been a substantial increase in the role of formal institutions in shaping human interactions. These range from local property, contract and zoning regulations to state and national regulations of water and land use, to international treaties, such as the World Trade Organization's (WTO 2017) role in regulating international commerce, nuclear arms treaties (UNODA 2017), and various treaties regarding the use of international sea waters (United Nations 1982) and $\mathrm{CO}_{2}$ emissions into the atmosphere (United Nations 2016). While formal institutional arrangements, especially their regulatory and constitutionally enforced guidelines and sanctions are a subject of daily discussion in political bodies and in the expanding variety of media outlets, they also have an impact on the degree of resiliency of communities in the face of exogenous factors associated with globalization. The scientific evidence is overwhelming in its conclusion that "The Commons" in many spheres is increasingly global (Dolsak and Ostrom 2003).

Political scientists and economists focus on how formal institutional arrangements affect community sustainability. This is found, for example, in Robert Dahl's classic study of city governance (Dahl and Rae 2005), Banfield and Wilson's (1963) analysis of the relationships between type of city government and degree of responsiveness to the preferences of various neighborhoods within the city, and Hernando DeSoto's (2000), Douglass North's (1990) and Baumol, Litan and Schramm's (2007) cross-national historical comparisons which show how formal institutional provisions for third party enforcement of contracts have a powerful impact, not only on economic growth but also on the development of civic life and political stability. Buchanan and Tullock (1962) and William Riker (1962) have shown the impact of different constitutionally mandated voting rules on the capacity of communities to pursue their interests. The ability of urban neighborhoods to organize sustainable collective citizens' organizations is affected by the presence or absence of formal institutional arrangements that create incentives or disincentives for residents to pay for the costs of these organizations (O'Brien 1975).

While each of the disciplinary traditions that focus either on formal or informal institutions are quite valuable by themselves in understanding the sources of resilience, or the lack of it, in communities faced with exogenous shocks, much greater insights can be gained by focusing on how the relationships between these two types of institutional arrangements affect the viability of different types of communities. A classic example of the role of informal institutional arrangements in shaping the development and sustainability of formal institutional structure is found, for example, in the effect of the Protestant non-conformist congregational participatory experience on the development of the New England town meetings in the 17th century and the subsequent devel- 
opment of the American federal constitution in the 18th century (Tocqueville 2004: Volume I: 37-40). Alternatively, Edward Banfield (1958) describes how culturally defined religious traditions in southern Italy produced an "amoral familism" that distrusted outsiders and thus weakened support for the formal governing institutions of a liberal democratic society. Similarly, Sheila Fitzpatrick's (1994) history of the Russian peasantry illustrates how the almost Hobbesian state of war of all against all in the Russian countryside in the 1920 s created an environment with an extremely low level of trust that, in turn, facilitated the ability of a relatively small group of ruthless but well-organized Communists to implement a forced collectivization.

Moreover, different levels of civil society and a market economy in pre-Communist European countries produced differences in the design and implementation of formal institutional structures when the Communists came to power. The weakness of civil society and a market economy in Russia prior to the Bolshevik revolution limited the opportunity for the development of a market economy or civil society to moderate the severity of the new authoritarian regimes. This meant that there were strong disincentives for individuals and households to develop bridging social capital. Instead, social networks in these countries were small and highly dense, including only the most trusted relatives and long-term friends (Rose 2000; Shlapentokh 1989). By contrast, in Poland and Hungary the existence of some significant elements of a market economy and a civil society prior to Communist rule resulted in a less oppressive form of authoritarianism that permitted the existence of compensatory economic civil society institutions, especially the preservation of the family farm and the Catholic Church, that co-existed with the structure of the command economy. With the collapse of Communism these compensatory mechanisms became a more dominant part of the new economy and a foundation for building civil society (Szelenyi and Kostello 1998).

While we have a good understanding of how the embeddedness of informal institutions prior to the attempted imposition of new formal institutional arrangements can impact the actual performance of the latter, we have less understanding of the reverse causality; that is, how can the imposition of specific types of formal institutional structures impact pre-existing informal institutional arrangements? This is a question of prime importance to understanding and ameliorating the challenges of community sustainability and reducing inter-community zero-sum conflicts in the 21 st century. Answers to this question will be addressed in the following chapters. But, before beginning that discussion, it is essential that we gain a fuller understanding of how exogenous shocks affect communities and the larger societies of which they are a part. 


\section{HOW EXOGENOUS SHOCKS AFFECT COMMUNITIES AND THE LARGER SOCIETY}

The effects of globalization's weakening of traditional community structures and attachments have been three-fold. The first, and most obvious, is the loss of economic foundations that gave rise to these communities in the first place. This has been the case, for example, with the demise of single industry factory towns. The second, and more profound effect for individuals who lose traditional community attachments is a spiritual malaise that turns to depression and destructive behaviors such as opiate addiction, violent acts toward others or suicide. The third, and the most disturbing consequence is the weakening of liberal democratic values that can produce fertile ground for the emergence of new "populist" pseudo-communities based on resentments toward outsiders embedded in racism, anti-immigrant sentiment, prejudice toward religious minorities and hostility toward science and educated elites, all of whom are seen by populist demagogues and their followers as the source of the destruction of an idealized traditional community way of life (Khazan 2017; Stiglitz 2018; Vance 2016).

Exogenous shocks to previously stable communities are not by any means a new story. A few millennia before the industrial revolution, Jesus of Nazareth, who Meier (2001) calls A Marginal Jew, proposed that a traditional society based on kinship should be replaced by other principles of social organization that share some remarkable similarities to the principles of liberal democracy, such as the dignity of the individual apart from his or her kin lineage and ethnic/religious affiliations, as well as community participation based on voluntary membership. These principles, of course, were altered in substantial ways, especially after Constantine's adoption of Christianity as the official religion of the Roman Empire, setting off a long and frequently bloody history of competition between various factions over what was the correct way to organize a Christian community, and later, over the relationship between the religious community, the economy and the secular state (see, e.g., Tawney 1926).

A useful starting point for understanding our contemporary struggles to conceptualize community and what sustains it is the emergence of liberal ideas in the Renaissance of the 14th to the 17th centuries, the Reformation in the 16th century and the Enlightenment in the 18th century. It is essential to appreciate how dramatic were the changes that occurred in each of these times and, most important, how these shifts in outlook were rooted in exogenous technological changes. This includes the use of geometry to introduce a three-dimensional perspective that is the hallmark of Renaissance art (Kubovy 1988), the invention of the printing press that made possible the rapid diffusion of new religious 
perspectives in the Protestant Reformation (Eisenstein 1979), and the focus on reason that was the central idea of the Enlightenment (Robertson 2015).

The modern discipline of economics, which began in the late 18th century is in many ways a culmination of liberal thought at the time, formalized in the notion of the market equilibrium produced by the bargaining involved in the buying and selling of rational individuals pursuing their respective self-interests (Heilbroner 1995). Formalized political science models in the liberal democratic tradition in the same period, such as the one described in The Federalist Papers (Hamilton, Madison and Jay 1787), focused on creating constitutions and by-laws that would encourage bargaining and tradeoffs within which individuals and communities with divergent interests and beliefs could live together peacefully.

Nineteenth and early 20th century sociologists certainly understood the enormous shift from traditional society to the rapidly changing industrial society of the 19 th and early 20 th centuries. One of the best-known typologies in the classical sociological tradition is Tonnies's (2001) distinction between gemeinschaft or community and gesellschaft or civil society. This categorization directs our attention to fundamentally different institutional principles that provide stability in traditional versus contemporary types of social organization. The institutional structure providing stability in the gemeinschaft emphasizes shared conformity to rigid cultural norms and values, while the institutional structure of the gesellschaft values a need to accommodate diverse individual interests. Thus greater attention is given to formal institutional means to protect those interests and resolve disputes between conflicting parties. This distinction provides an insight into the contemporary conflicts between rural and metropolitan communities in politics and personal lifestyle, where the more homogeneous population in most rural places more closely approximates the gemeinschaft while the more diverse population in metropolitan places more closely approximates the gesellschaft form of social organization (Kron 2013). A similar typology is described in Durkheim's contrast between "mechanical" and "organic" societies, in which solidarity in the former is maintained primarily through "repressive" sanctions, while in the latter there is greater reliance on "restitutive" or civil/contractual law (Durkheim 1994: 200-32).

The discipline of sociology was formed as a reaction to the overly individualistic and rationalistic emphasis of 19th and early 20th century thought. Thus, in many ways the discipline has roots in the 19th century romantic-conservative reaction to the social disorganization of the French Revolution, and the Enlightenment ideas that were associated with it (Nisbet 1993; Zeitlin 2000). This world view is expressed most clearly in Durkheim's classic empirical work in his study of The Division of Labor in Society (1893 [1994]), On Suicide (1897 [2006]) and The Elementary Forms of Religious 
Life (1912 [2001]) in which he accepts the reality of the division of labor in modern society but focuses on the role of non-rational sentiment, ritual and the collective conscience of the group as an essential glue holding human social groupings together. The absence of social attachment, he argues, produces anomie or normlessness, which is associated with both personal (e.g., suicide) and social (e.g., industrial conflict) disorganization. In short, a major focus of the sociological tradition in the 19th and early 20th centuries was to resurrect a perceived loss of community through a rehabilitation of non-rational aspects of human life (Lichbach and Seligman 2000).

\section{TECHNOLOGY AND EXOGENOUS SHOCKS TO COMMUNITIES}

Sociologists are most apt to be familiar with the disruptive effects of technological change on the social organization of human communities during the industrial revolution, through the scholarly writings of Marx on the alienation of the industrial worker (Marx 1994; Ollman 1976) and Durkheim's (1897 [2006]) description of anomie. A wider audience may be sensitized to this earlier period by reading Dickens's (1859 [1999]) heart-wrenching novel, The Tale of Two Cities, that focuses on dislocation, abandonment and the breakdown of civil discourse.

Less well known is the much longer story of community disruption caused by earlier technological changes. Gerhard Lenski (1984) traces the effects of technological change that increased economic inequality as human societies evolved from hunting and gathering to horticultural societies, with the introduction of the hoe, then to agricultural society, with the introduction of the plow, and then to early industrial society, with the invention of the steam engine. Successive technological advances increased the amount of surplus produced, thus making it possible for the emergence of elites and class systems. His analysis of the growth of inequality, however, ends on an upbeat note as he describes how late industrialization in the 20th century produced enormous technological advances that provided sufficient surplus for elites to eventually acquiesce to the adoption of the welfare state adjustments in Western Europe and North America that caused, with the assistance of the post-World War II economic boom, a substantial reduction in inequality in those nations. Schumpeter (1950) argues that the growth of this surplus, and most importantly the pragmatic "anti-heroic capitalists" market orientation explains why Marx's prediction of an inevitable zero-sum conflict between proletariat and capitalists did not occur in industrialized countries; ironically, Communism took hold in the less developed, barely out of feudalism, Russian Empire. 
A critical point here, however, is that Lenski's book was published in 1966. Recent research by Piketty (2014) and Bourguignon and Railton (2015) shows that the growth of technology in communication and transportation since the 1970s has produced dramatic shifts in inequality both between and within nations. Inequality between nations has declined markedly - largely due to the expansion of the Indian and Chinese economies - while, at the same time, inequality within Western nations, especially the United States, has increased rapidly and shows no sign of abating.

It is impossible to ignore the material consequences and associated effects of technological change on the material conditions of human beings affected at a given time period. But equally important is the impact of new technology in weakening or destroying a familiar community on the individual who has lost that attachment. This is true even if the former community was, from our contemporary point of view, very unjust. Erich Fromm (1965) suggests that the freed serf did gain more freedom, in principle at least, but lost the security of the old order that was soon replaced by the anxiety of "what is my place in this world?" This explains, for example, recent voting studies especially in the United States, but also in rural areas of Western Europe, where individuals vote for demagogues who promise to return them to an idealized and secure community of yesterday (Green 2017).

The common thread found throughout pre-history and history is that community attachments provide an essential connection not only to the material and psychological needs of human beings, but also to a deeper need to connect with the human spirit. In this regard, community is a spiritual as well as a material entity. This understanding of the spiritual dimension of community has been articulated in the major religions, but also is found in a much larger body of literature, poetry and writings that focus on broader questions of the meaning of human life. Examples of this larger view are found in William James's Variety of Religious Experiences (2012), Vikktor Frankl's Man's Search for Meaning (1959 [2006]), Erich Fromm's Escape from Freedom (1941 [1965]) and the proliferation of 12-step recovery programs in the 20th century (Alcoholics Anonymous 2001; Kurtz 1991). All of these writings address the role of community in providing an essential source of sustenance to the human spirit, which for many is somehow connected to a Spirit of the Universe, God, gods or a Higher Power.

It is especially important to avoid overly romanticizing the concept of community. Individuals in Western countries hear on an almost daily basis how forms of Islamic fundamentalism claim to be preserving a traditional community but also provide a bulwark against those aspects of modernity that would improve the lives of ordinary people (Watt 1988). Some communities in Western countries, especially in the United States, create attachments that can be quite harmful to their members. Isolated religious cults, for example, 
oftentimes psychologically, physically and sexually abuse their members. Most tragic are communities that otherwise provide significant benefits to their members and the larger society but because of their suspicion of outsiders protect abusers who cause serious harm to their members. In addition, once exposed these unhealthy communities can generate a broader distrust of a whole class of organizations that may seem, on the surface at least, to share similarities with them. This is seen, for example, in the sexual abuse scandals in the American Catholic Church, highlighted in the film Spotlight (2015), and the abuse and relentless harassment of members who attempt to leave the isolated ultra-orthodox Hassidic Jewish community in New York, shown in the documentary One of Us (2017).

\section{GLOBALIZATION, MASS SOCIETY AND INSTITUTIONAL RESPONSES}

The impact of globalization on the sustainability of traditional communities is a worldwide phenomenon, but it expresses itself differently in different parts of the world. In the Middle East, South Asia and North Africa it is seen in the often-violent reactions to globalization, expressed in a desire to return to some mythical golden community of the past. The challenge of moving beyond insulated tribal community identities to larger pluralistic civil societies has been very uneven in these regions (Beinin and Vairel 2013).

Post-Soviet efforts to create grassroots collective citizens' organizations, at both the local and regional levels, have faced a unique set of institutional challenges. The Soviet governing model, institutionalized after the 1929 collectivization, destroyed all intermediary institutions and organizations that the Communist leadership perceived as a threat to its power. This has posed serious obstacles, for example, to the development of smallholder agricultural cooperatives (Upadhyay 2006).

After the enormous destruction of World War I and World War II, West European nations developed a complex cross-national formal economic institutional structure that removes the structural bases for zero-sum conflicts between the member nations, while at the same time preserving a relatively high degree of autonomy for divergent community identities within nations (European Union 2012; Leader Program 2018). There are, of course, serious challenges to the integrity of the European Union (EU) coming from Brexit and the rise of xenophobic right-wing populism in a number of EU member countries, as well economic integration challenges due to differences in the relative strength of each member nation's economy. But, so far, the overall EU institutional structure has been resilient (Grabbe and Lehne 2016).

The United States is in a unique position with respect to globalization and community attachment. Because, as Tocqueville observed in the 1830s, it 
possesses a core cultural obsession with individuality, yet historically has possessed a formal institutional structure, through its federal constitution, that has provided an opportunity for sub-cultural communities to emerge within a framework that regulates how inter-communal relations will be handled. He noted, however, in prescient observations, that the core challenge for the United States is to maintain both the informal and formal institutional barriers that restrain the potential dangers of the "tyranny of the majority" (Tocqueville 2004, Volume I: 283-364). This is certainly relevant to understanding the current rise of "populism," with its attendant racism and xenophobia (Kabaservice 2017).

The relationship between a highly individualistic culture that places a premium on individual success, with its effect of heightening economic inequality and decline of community, has long been a theme in American literature and sociology. Theodore Dreiser's An American Tragedy (1925 [2010]) and James T. Farrell's Studs Lonigan Trilogy (1932 [2001]) are among the best-known works of fiction in this genre. Studies of community decline and its attendant social and personal disorganization was a major focus of the early American Chicago School of sociology as well; notably, Thomas and Znaniecki's The Polish Peasant in Europe and America (1918-20 [1996]). More recently, Kurt Andersen's Fantasy Land: How America Went Haywire (2017) focuses on how the unique American obsession with individualism has produced some long-term negative barriers to building a healthy community spirit.

At the same time, it is important to understand how this tendency toward the separation of the individual from the community is affected by underlying structural economic conditions. In the mid-1960s, during the height of President Johnson's Great Society, his Assistant Secretary of Labor Daniel Patrick Moynihan published a report on the Negro Family in America. The report became a subject of controversy, largely because its description of social pathology in northern urban enclaves of African Americans offended what was up until then a largely middle-class civil rights movement to bring about legal racial equality. Nonetheless, Moynihan's report contained some straightforward but disturbing data showing that the northern communities to which African Americans moved during the Great Migration up through World War II contained, by and large, less stable family structures than were found in the segregated southern communities that they had left. Moynihan's main point, which was often lost in the debate that followed, was that the high level of single parent households in the northern ghettos was due to the absence of economic opportunity for men (Wilson 1980, 2012). The goal of the report was to provide a justification for providing federal government support for increased training and opening up opportunities in the skilled trades (Rainwater and Yancey 1967). In short, Moynihan's report was intended to 
be a scholarly justification for a formal institutional adjustment to strengthen local African American neighborhood communities, through the process of providing new formal institutional mechanisms to assist male job seekers.

The economist Paul Collier (2018) makes a similar point in addressing the structural causes of personal and social disorganization in white as well as Black working-class households in "rust belt" declining cities in both the United States and the United Kingdom. He goes a step further than Moynihan proposing that the resources to make these disadvantaged places viable again should come from a tax on the gains or "rents" (in the economist's use of the term) that individuals and firms in thriving metropolitan areas have received from "agglomeration" - that is, the concentration of human and material capital - which is dependent to a significant degree on the larger society's "public goods"; for example, national security, law and order, third party enforcement of contracts, knowledge-generating universities and other national taxpayer-funded organizations and institutions. His argument will be described in more detail in Chapter 5 .

One of the most striking trends in the United States in the early 21 st century is that the decline of community and associated pathology that Moynihan described with respect to the 1960s African American population in northern cities has now expanded to a much larger portion of the American population. This is seen most dramatically in the situation of less educated rural whites who have experienced a significant decline in life expectancy. The book, Hillbilly Elegy (Vance 2016), written by a third-generation descendant of Kentucky hill people who migrated to Ohio for well-paying jobs in the post-War years, describes the breakdown of community and attendant personal and social disorganization as those high-paying jobs disappeared, through robotics and transfer of production overseas.

The proximate cause of the poor health and other quality of life indicators among rural and less educated whites is the dramatic rise in opiate addiction (Bernstein and Ingraham 2017). A deeper look into the world view of these individuals, however, suggests that their lifestyle is actually a symptom of a much deeper malaise. The Dalai Lama and Arthur Brooks (2016), in an article published four days before the 2016 American Presidential election, add a spiritual dimension to the mass society argument. The article, titled, "Behind Our Anxiety, the Fear of Being Unneeded," notes that on an objective basis, material conditions have never been better, including substantial reductions in deaths among infants and children and a huge rise in literacy worldwide. And yet, they note the tremendous hostility toward refugees and migrants who are fleeing from war zones. They argue that the root cause of this anxiety and 
anger toward immigrants is found in the swath of residents of these rich countries who feel that they are no longer needed. They observe that:

Being "needed" does not entail selfish pride or unhealthy attachment to the worldly esteem of others. Rather, it consists of a natural human hunger to serve our fellow men and women. As the 13th-century Buddhist sages taught, "If one lights a fire for others, it will also brighten one's own way." This helps explain why pain and indignation are sweeping through prosperous countries. The problem is not a lack of material riches. It is the growing number of people who feel they are no longer useful, no longer needed, no longer one with their societies. In America today, compared with 50 years ago, three times as many working-age men are completely outside the workforce. This pattern is occurring throughout the developed world - and the consequences are not merely economic. Feeling superfluous is a blow to the human spirit. It leads to social isolation and emotional pain, and creates the conditions for negative emotions to take root. (Dalai Lama and Brooks 2016: A29)

The relationship between social dislocation and the rise of intolerance has been articulated and embedded in extensive data in William Kornhauser's (1959) theory of "mass society." He describes the economic and social conditions that support modern anti-democratic movements, such as Fascism in Germany and Italy, Communism in Russia and McCarthyism in the early Cold War period in the United States. The theory integrates both economic and cultural elements, focusing on the appeal of demagogues to those whose attachment to democratic institutions declines as their position in society either has been weakened or eliminated by rapid economic and social change. Kornhauser points out that:

large numbers of people do not respond to totalitarian movements primarily from the standpoint of economic calculus; but instead, they respond to the nihilistic tone of totalitarian movements, as an expression of their feelings of resentment against the present and hope for something completely new in the future ... the strongest response to the totalitarian appeal is not to be found among those who are involved in class organization and class struggle; on the contrary, the strongest response comes from people with the weakest attachment to class organizations, or any other kind of social group. A totalitarian movement attracts socially isolated members of all classes. (Kornhauser 1959: 48-9, emphases in the original)

Hannah Arendt (1968) in her treatise on totalitarianism explains why a totally rational explanation of the thought processes of the followers of Hitler or Mussolini, as well as the contemporary followers of the populist leaders is so difficult (Bernstein 2018). The working-class followers of Trump, for example, may be voting against their objective economic interests, but they typically are not members of a working-class interest-group, such as a labor union, but rather part of what Arendt calls the mob (1968: 106-17) and which Tocqueville, in the 1830s, feared as the "tyranny of the majority" (2004, 
Volume I: 288-91). It is the weakening of intermediary institutions and organizations that makes the demagogue appealing to so many seemingly disparate social categories of individuals. Once in power, of course, the key to the totalitarian's success is to ensure that these intermediary institutions and organizations remain weak (Lipset 1981: 102-3).

Moreover, a rapid breakdown of traditional community attachments provides the fertile soil for new types of religions that provide a biblical-style account of the origins of the group, a devil who is responsible for spoiling the group's identity and a path through which the group will be restored to glory. Karen Armstrong (2011) describes how fundamentalist/millennial religious movements emerge during periods of great social, economic and political turmoil. Burleigh (2000) provides convincing evidence that Hitler's Third Reich was essentially a "religious" movement.

The community problem in America, however, is not merely one that affects the most angry and violent fringe groups that are made up of the most disconnected individuals. Another aspect of the problem is the separation of individuals into essentially walled-off enclaves where they only have empathy for members of their own group. Robert Putnam (2015) describes in his recent book, Our Kids, the decline of connectedness, or social capital, in the larger society as individuals from different social and economic strata increasingly have very little real human contact with one another. This results in a decline in what Bellah terms, "habits of the heart" (Bellah et al. 1996). Bill Bishop (2009) refers to this as The Big Sort; that is, the increased separation of persons with different social, cultural and economic characteristics into both spatial and media niches. This contributes to the growing "tribalism" in Western nations, especially the United States, where the isolation of one group from another presents a serious barrier to a reasonable discussion of the compromises necessary to deal with the challenges of adapting communities to an increasingly globalized environment.

The extreme isolation of communities from one another helps to explain why citizens who are better off economically and socially - that is, stable careers and family structures - oftentimes have a difficult time understanding the challenges facing those families such as those described in Hillbilly Elegy (Vance 2016). It also suggests that there is more truth than we would like to admit about what appears to many rural white voters as the arrogance of metropolitan "intellectual elites."

Gordon Allport's classic summary of research on the sources of prejudice, written in the middle of the 20th century, explains the relationship between the separation of communities and hostile attitudes toward "out-groups." When individuals with different social or economic attributes interact in equal status positions there is a reduction in prejudice. Conversely, when individuals 
interact in unequal status positions there is an increase in prejudice (Allport 1958: 250-68).

Varshney's (2002) study of communal violence in India is especially instructive in this regard. He found that when a Hindu-Muslim inter-communal conflict arose over some alleged offense committed by one group against the other, there were some places where the violence was quite minimal, while in other places it was quite extreme. The researcher found, consistent with Allport's earlier research, that in places where Hindus and Muslims belonged to the same labor union or social group, the tension was much lower, while, conversely, in places where the members of the two religious communities had little equal status social contact the violence was most extreme.

\section{INSTITUTIONS, SOCIAL NETWORKS AND ADAPTATION TO SOCIAL CHANGE}

Sociologists tend to focus on informal institutions set within a culture that provides, to a greater or lesser extent, the guidelines within which individuals at different levels of social organization are supposed to behave. Especially relevant here are the ways in which informal social networks provide specific options (or lack of options) to deal with out of the ordinary exigencies. In recent years New Institutional Sociology (NIS) has provided us with a wealth of empirical studies showing how economic distribution systems, including markets, regulations (or lack of), level of social welfare supports and inequality are embedded in informal institutional arrangements (Brinton and Nee 1998; Granovetter 1985). As noted earlier, this accounts for the easier adaptation of Hungary and Poland to the collapse of Communism than was the case with post-Soviet Russia (Szelenyi and Kostello 1998).

At the same time, it is important to recognize that it has been the acceptance of Poland and Hungary into the EU that has provided a massive formal institutional support network for their emerging economies and, at least initially, has led to the integration of these countries into the liberal democratic laws and practices of the West European country members. The current challenge facing Poland, Hungary and the EU is the extent to which being embedded in a formal institutional structure, specifically the EU rules protecting diverse citizens' rights, fairness of national government institutions and permitting the growth of civil society can be sustained. So far, the threat by the EU to cut off funds to Poland and Hungary for not adhering to EU rules has not been sufficient to reverse the movement toward anti-liberal laws and practices (Erlanger 2018).

Finally, it should be noted that institutional adjustments in different places within the same country can produce substantial variability in the impact of national-level institutional changes. This is illustrated in rural regions of post-Soviet Russia, where differences in the manner in which provincial 
(oblast) governments' formal institutional supports for smallholder household farms produced different outcomes in the degree to which individual communities and regions were able to adapt to an emerging market economy. During a time of hyper-inflation in the early years after the collapse of the Soviet Union, smallholder farmers in Belgorod oblast (province), Russia, made significantly greater gains in comparison to their counterparts in nearby Rostov oblast (province). These gains were a direct result of the Belgorod governor's initiation of a government-backed program in which loans to smallholder farmers were made in kilos of agricultural products - for example, number of kilos of poultry meat - rather than in the hyper-inflating official Russian currency, the ruble. Borrowers paid off loans in non-inflationary kilos of meat. These loans provided a way for farmers to increase their income by purchasing equipment to process meat or milk or to expand the size of their barns. The governor in Rostov oblast did not develop any institutional ways to cope with the extremely high interest loans and thus his smallholder farmers were less likely to take out loans and, in turn, their production and processing capabilities did not improve (O'Brien, Patsiorkovsky and Dershem 1998). (See also O'Brien (2012a); O'Brien and Patsiorkovsky (2006); and O'Brien, Wegren and Patsiorkovsky (2005) for additional post-Soviet regional comparisons.)

Scholars in the New Institutional Economics (NIE) tradition recognize how formal institutional changes can produce changes in informal institutional arrangements that affect the way in which different societies adjust, or do not adjust, to the shocks created by technological change.

An illustration of how carefully developed formal institutional arrangements can facilitate the adaptation of traditional cultures to the challenges posed by globalization is found in the United States Land Grant Universities system, begun in 1862 with the Morrill Act, and expanded to historically Black universities and colleges) in 1890. The land grant system created and has supported high quality universities, and through the United States Department of Agriculture (USDA) Agricultural Experiment Station and the USDA Agricultural Extension Service not only has brought scientific information to small farmers, but also has helped to provide assistance to create more sustainable rural communities. Today, Extension Agents work in both urban and rural areas conducting a variety of community-building programs in health, safety, workforce development and entrepreneurship (APLU 2017; NIFA 2017).

In 1994, the USDA created the Tribal College Initiative Grants (2018) that extended the Land Grant mission to Native American reservations. This program can be seen as a formal institutional approach to address a long-standing tension between the Native American tribes and the US federal government. The various Native American tribes have sought for several centuries to preserve their cultural identities in the face of what they have seen as insensitive and disruptive forced efforts to assimilate them into mainstream 
American culture and society. The most horrific of these efforts was the attempted forced acculturation of children in Indian boarding schools, which frequently resulted in suicides. The Tribal College Initiative Grants program addresses this historic problem in two ways. The first is to provide support for training for Native Americans in their own communities to become better prepared to work and live in a globalized world. The second, and equally important, goal is to help maintain the institutions that preserve traditional tribal culture. The larger significance of this program is that it demonstrates that formal institutional structures, properly designed and implemented, can help overcome historical tensions between traditional cultures and the demands for adaptation into a rapidly changing world. There has been variability in the degree of success of the tribal college program from one place to another, but the fact that there have been many empirically documented successes supports the notion that formal institutional structures can find ways for very traditional communities to accommodate to social change, without sacrificing their own integrity (O’Brien, Phillips and Patsiorkovsky 2005).

Another formal institutional initiative that has had a profound effect in strengthening communities has been the cooperative movement, formed with the Rochdale Principles in England in 1844 (Lambert 1965), and since expanded to many other places throughout the world (Cook 1995). The institutional foundations for this organizational form were the informal institutions - churches, schools and farmers helping one another - that supported the social organization of small rural communities. In the United States, the capacity of cooperatives to grow and, in turn, to help sustain rural communities, was enabled by formal government institutions that provided them with protection from anti-monopoly laws and eventually provided support for the reforms instituted during the progressive era in American government (Schneiberg, King and Smith 2008). The County Extension Agents, created through the Land Grant College and University Act, actively supported the organization of the Farm Bureau Cooperative which eventually became one of the most powerful agricultural cooperatives and lobbying groups in the United States (Olson 1971: 153-8).

At the same time, it is important to recognize how formal institutions that were ostensibly designed to listen to "the voice of the people" can have unintended negative effects on relationships between communities. The referendum, as illustrated in the chaos surrounding Brexit, incentivizes "winner take all" games between communities with very different views of life (Norris and Inglehart 2019). Alternatively, institutional arrangements that provide contending parties with an opportunity to trade their votes for something in return, encourage communities to bargain and adopt pragmatic rather than ideologically extreme positions (see Banfield and Wilson 1963; Buchanan and Tullock 
1962; Riker 1962) and thus, over time, build both bonding and bridging social capital (Collier 2018: 201-15; Lilla 2017: 105-11; O’Brien 2012b, 2018).

Mark Lilla contrasts working within the institutional structures of liberal democracy and the romantic appeal of less incremental solutions. He writes that:

The framers of our [US] constitution [in the late 18th century] arranged things so that political action would have to be filtered through institutions that require consultation and compromise, and would depend on a system of frequent elections, checks and balances, the autonomy of the civil service, civilian control of the military, the writing of laws and regulations and their impartial enforcement. ... They wanted to spare the United States the fate of Europe [at that time], which they saw as wracked for centuries by the arbitrary rule of tyrants, court intrigues, coup d'etat, wars of religion, and republican factionalism. ... How much better, they thought, to canalize political energy into institutions, while making them as transparent and participatory as possible.

Romantics chafe at this undramatic conception of politics. They prefer to think of it as a zero-sum confrontation ... the People against Power, or Civilization against the Mob ... And what could be more dreary than the history of parties and public administration and treaties. (Lilla 2017: 106-7)

There is certainly compelling evidence of the important role of slogans, movements and especially organized protests in motivating politicians in a liberal democracy to engage in serious discussion, debate and compromises within constitutionally defined legislative bodies. But, it is precisely these political processes that have led eventually, typically over a considerable period time, to major social changes, such as the Thirteenth Amendment in 1865 that outlawed slavery, the Nineteenth Amendment in 1920 that granted women the right to vote, and the Civil Rights Act in 1964 and the Voting Rights Act in 1965 that overturned Jim Crow segregation laws and provided legal protections to African Americans. Lilla's main concern is when progressive activists disregard formal political institutions altogether and the tedious long-term work involved in achieving "progressive goals" within them.

While globalization is a central contributing factor to the contemporary decline of many communities, there is by no means a simple causal relationship between it and the personal and social pathologies that are of great concern today. Most important, there are a variety of institutional adjustments that can substantially moderate the negative effects of community decline and the rise of closed-off communities. The tendency of many approaches to the problem of community sustainability is to focus on one causal relationship but to exclude other causal directions. For writers who tilt to the left or progressive side of the political spectrum the loss of community is attributed to the growth of economic inequality, while those who tilt to the right tend to see the decline of community attachment more in terms of cultural trends toward extreme 
self-expression. Both of these views contain some truth, as they did in the 19th century, when the early social scientists were attempting to understand, and provide an avenue for intervention, in the social disorganization of the industrial revolution. (See, e.g., Zeitlin (2000) and Nisbet (1993) for alternative interpretations of the historical evolution of radical rationalist versus romantic conservative perspectives in the sociological traditions.)

Yet, despite the different emphases of Marx and Durkheim on alienation or anomie, respectively, it is clear that both were speaking of a drastic dislocation, not just from work or lifestyle, but a more fundamental disconnection that best can be described as a spiritual malaise. In this regard, their observations from the earlier period provide some valuable insights into how the disruptive effects of technological change can affect an individual's attachment to his or her community.

The critical challenge today, as it was at the time of the industrial revolution, is to identify how to support sustainable communities that can at once meet the basic human attachment needs of their members and adapt to the realities of technological change. Long after the deaths of Marx and Durkheim, institutional structures were developed to adapt to the modern factory system. The old social organization of weavers in the cotton industry, for example, could not be resurrected, but legislation in Western Europe and the United States eventually created formal institutional supports for labor union formation, as well as child labor laws, which were adaptations to the realities of the factory system that had replaced the cottage industries (Smelser 1959). Similarly, new formal institutional adjustments are necessary to support viable communities in the current age of globalization.

\section{FORMAL AND INFORMAL INSTITUTIONAL EFFECTS IN DONOR-FUNDED COMMUNITY DEVELOPMENT PROGRAMS}

Post-World War II Modernization Theory (Gilman 2004) can be viewed as an approach to community-building in the face of the challenges posed by globalization in former colonial nations. The central question posed by those who subscribed to this approach was, how could the "backward" elements of "traditional society" be overcome so as to provide a way for the citizens of these new nations to develop their economies and enjoy the material benefits experienced by citizens of Western nations? The answer underlying this approach was the rapid introduction of what were seen as more rationally based modern institutions. Unfortunately, the promoters of this approach did not seriously consider how to deal with the complex task of linking local village-level institutions to larger institutional and organizational structures. This resulted in projects that were not sustainable. 
The discrediting of modernization theory has led to a reorientation of development approaches that begins with the assumption that linkages to organizational structures outside the local area will not be sustainable unless the preferences and institutional structures of local actors and organizations are brought into the planning process at the very beginning. Examples of projects developed along these lines, that are funded by the USAID, include the Cooperative Development Programs that assist smallholder cooperatives to gain a better foothold in the agricultural value chain (O'Brien and Cook 2016; O'Brien, Banwart and Cook 2013; Meador et al. 2016), as well as the recently initiated Local Works Program (Localworks 2015) that begins the planning of development programs by first identifying what goals are important to the local residents and what local social network structures can facilitate and/or hinder the accomplishment of these goals.

An especially compelling illustration of how an institutional approach to development can have substantial positive effects on community-building is the effort by the post-genocide Rwandan government to develop institutional structures to heal the wounds of past inter-communal conflicts and create sustainable ways to prevent such events from occurring in the future. One of the most notable in this regard has been the institutionalization of the "genocide remembrance" program in Rwanda that includes official annual remembrance ceremonies and a national museum, as well as mandated civic education to install tolerance values and norms in the population (Clark 2018). Most important, the Rwandan government has recognized that economic divisions between communities heighten ethnic tensions. To overcome these divisions, the government has developed new institutional guidelines to support economic development through smallholder agricultural cooperatives that link diverse communities into the broader national and international economy. This has included legislation that requires women to hold at least 30 percent of leadership positions in cooperatives (Meador and O'Brien 2019).

In the following chapters, we will look at numerous empirical examples in Sub-Saharan Africa, the former Soviet Union, the EU and the United States that illustrate how formal institutional arrangements can be created to encourage the development of resilient communities in the face of the exigencies posed by globalization. The next chapter will describe why the most effective way to conceptualize the challenges of globalization to community sustainability and provide a path to develop institutional remedies to address them is the "public goods" framework (Olson 1971). 